\title{
Martín de Riquer: profesor y estudioso. Tres calas Carlos Alvar
}

Se ha repetido ya muchas veces que la larga vida del Prof. Martín de Riquer Morera (1914-2014) estuvo marcada por una dedicación continua al estudio y al trabajo, fruto de una curiosidad insaciable y de una capacidad poco frecuente: con el mismo entusiasmo se aplicó a la literatura catalana medieval, a la castellana o al Quijote; a los cantares de gesta franceses, a Chrétien de Troyes y a los trovadores occitanos; a la heráldica o al armamento de los caballeros... Es verdad, y nos han quedado sus numerosísimas publicaciones para atestiguarlo.' Con menos frecuencia se ha insistido en su pasión por la docencia: sólo quienes siguieron sus clases dan testimonio del entusiasmo que ponía en cada una de ellas, desde el principio hasta el final. Pero investigación y docencia son dos vertientes de un mismo edificio, y no podrían haber existido la una sin la otra.

La trayectoria investigadora de Riquer empezó con juveniles veleidades de helenista, y su interés por el mundo clásico hizo que simultaneara los estudios sobre la literatura grecolatina con el de los humanistas catalanes de los siglos XIV y XV: ahí surge un librito de divulgación sobre el humanismo catalán (Riquer 1934) y, un año más tarde, la edición de las obras de Antoni Canals, escritor catalán del siglo XIV (Riquer 1935). Martín de Riquer apenas tenía 21 años.

A partir de 1942, Riquer empezó a enseñar Literatura española en la Universidad de Barcelona, dedicándose en especial a la Edad Media, tanto castellana como catalana y provenzal: es en este momento cuando se puede ver un cambio

\footnotetext{
1. Para un bosquejo biográfico es imprescindible ver el libro de Gatell \& Soler (2008). La bibliografía fue recogida por Leonor Vela (1991). La revista Anthropos dedicó completo su número 92, enero de 1989 , a Martín de Riquer. Investigación filológica e historia de una cultura.
}

o, quizás sería mejor decir, una notable ampliación de sus intereses. El resultado de aquellos cursos fueron sus primeras publicaciones sobre los trovadores: ya en 1940 se había acercado a las poesías de Bernart de Ventadorn, traduciéndolas y poniéndolas al alcance de un público culto (Riquer 1940), igual que hizo unos años más tarde con las albas provenzales (Riquer 1944a) y, con la edición de Cerverí de Girona (Riquer 1947), llevada a cabo con los escasos medios de los que se podía disponer en aquel momento de la posguerra mundial y del aislamiento español. En todo caso, la necesidad de textos y de otros materiales didácticos para sus estudiantes le llevó a traducir y comentar las poesías de los más destacados trovadores del siglo XII (Riquer 1948a), y a elaborar un Resumen de literatura provenzal trovadoresca (Riquer 1948b).

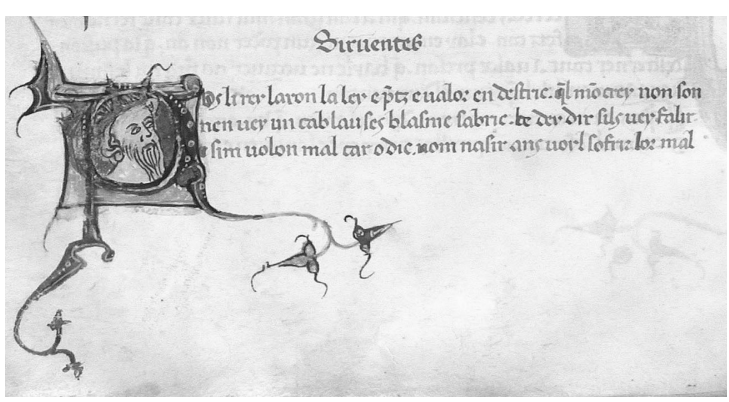

El principal testimonio manuscrito de la obra de Cerverí de Girona (Barcelona, Biblioteca de Catlunya, ms. 146).

Esta dedicación a los trovadores provenzales no impidió que Martín de Riquer sintiera interés por otros géneros y por otras literaturas: seguía de este modo el consejo que le había dado Karl Vossler en 1944 de que no se dedicara sólo a una lengua de la Romania, sino que ampliara su estudio a las distintas modalidades lingüísticas de la península ibérica, y al provenzal, al francés y al italiano; es decir, que se convirtiera en ro- 
manista al modo europeo, o más concretamente germano-italiano.

Las distintas obras que había publicado Riquer sobre los trovadores habían llamado la atención entre los colegas españoles. Fue en especial Dámaso Alonso — quizás el único romanista español del momento- quien alentó a Riquer para que continuara en la misma línea de trabajo. Así, como director de la «Biblioteca Románica Hispánica» de la editorial Gredos, le propuso en octubre de 1950 que redactara para la colección un volumen, de unas 150-200 páginas, como «lntroducción a la filología provenzal» y una «Gramática provenzal descriptiva e histórica». Riquer aceptó con entusiasmo el encargo e incluso aventuró un título, Introducción al estudio del provenzal literario. Conocemos estos datos gracias a la correspondencia cruzada entre Dámaso Alonso y Martín de Riquer. En la misma carta de aceptación, nuestro maestro hacía saber a su corresponsal que acababa de entregar a la imprenta una traducción de la Chanson de Roland y una antología de cantares de gesta franceses, de unos 6.000 versos, para uso de los estudiantes universitarios. Se inicia de este modo otro de los grandes proyectos de Riquer, el dedicado a la épica en general y más en concreto a la epopeya francesa. ${ }^{2}$ El manual de filología provenzal no llegó a puerto y tampoco vio la luz la traducción de la Chanson de Roland de la que hablaba Riquer en su carta, pero como tantos otros trabajos, el esfuerzo no sería en vano, ya que con el paso del tiempo cobrarían envergadura ambas líneas de investigación: la antología de los trovadores se perfilaba como una serie de tres volúmenes, a la vez que la Chanson de Roland daría lugar a los capítulos iniciales de un nuevo libro para la editorial Gredos (Riquer 1952a) y a la publicación de la traducción del cantar de gesta francés en la popular colección Austral (Riquer 1960).

Lírica de los trovadores y poesía épica se habían convertido en dos núcleos del quehacer investigador de Riquer. Es natural que Dámaso Alonso, a caballo entre la erudición y la activi-

2. La correspondencia de Dámaso y Alonso y Martín de Riquer referente al libro de Gredos es extractada y publicada por Isabel de Riquer en el prólogo a Riquer (2009). dad editorial, se esforzara en encontrar un punto de equilibrio entre los intereses académicos y los comerciales, que intentara recuperar los trabajos de Riquer sobre provenzal que habían visto la luz en los años 40 y unirlos a las nuevas preocupaciones de su amigo barcelonés, centradas en la poesía épica. Por eso le propuso que escribiera unos Orígenes de la(s) Literatura(s) Románica(s), donde encontrarían cabida ambos aspectos y, además, se enriquecería con nuevas aportaciones sobre la narrativa y, más en concreto, sobre la materia de Bretaña.

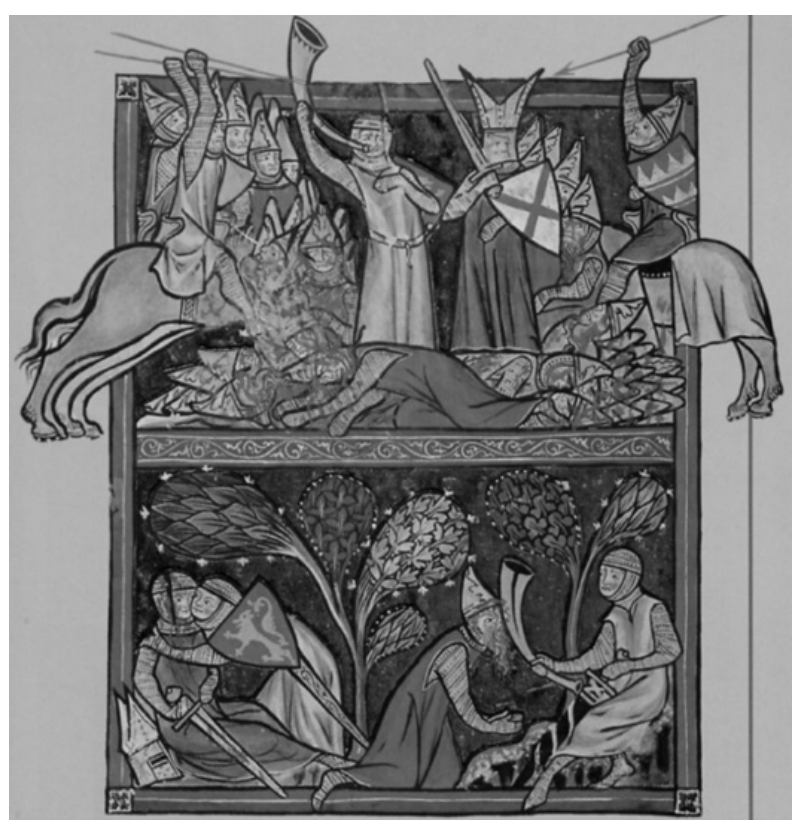

Dos momentos en la célebre escena de la muerte de Roldán.

Sin embargo, Riquer, que a la sazón contaba 37 años, es posible que viera las cosas de modo diferente: había trabajado sobre lírica trovadoresca, por lo que volver al tema no tendría para él el atractivo de la novedad y, sobre todo, nuestro filólogo tenía en mente un amplio proyecto sobre los trovadores en tres volúmenes, de los que ya había concluido los dos primeros en 1951.3 Parece claro que no quería desviarse de esta idea. Mientras tanto, el proyecto de la épica sufría continuos retrasos obligados por la tardanza de los envíos postales que debían hacerle llegar la bibliografía necesaria y por el

3. Así lo comenta Riquer a Dámaso Alonso en carta fechada el 5 de septiembre de ese año. 
tiempo que le robaban otros compromisos: el empeño que mostró a Dámaso Alonso en que el libro de la colección «Biblioteca Románica Hispánica» llevara en el título una referencia a los cantares de gesta franceses, frente al deseo -más comercial- del director de la serie de que apareciera una alusión a la épica española, no hacía sino poner de manifiesto la distancia en los planteamientos de ambos estudiosos y la idea de Riquer de reutilizar el prólogo inédito de su traducción de la Chanson de Roland. El caso es que tras las esperas y las dificultades, las discusiones epistolares y el agobio del trabajo, vio la luz Los cantares de gesta franceses (sus problemas, su relación con España) en 1952.4 El libro, según su autor, tenía una doble finalidad, dar información acerca de la poesía épica francesa de los siglos XI al XIII y, por otra parte, señalar las relaciones de esos poemas con España, ya sean aquellas geográficas, temáticas o genéticas. Los cantares de gesta franceses presentaba en sendos apéndices el Fragmento de la Haya y el ensenhamen de Guiraut de Cabreira en el que el trovador enumera numerosos cantares de gesta que debería saber su juglar Cabra, además de otras obras. Cuatro años habían transcurrido entre las clases de 1948 y el libro impreso. 5 Cinco años transcurrirían entre la edición española y la versión francesa: es un período de tiempo escaso, si se tiene en cuenta la lentitud de la difusión de la obra fuera de España, su aceptación en los ámbitos universitarios francófonos, la labor de revisión y de traducción. Pero a veces en pequeño lapso de tiempo se concentran varias publicaciones importantes sobre un mismo tema; y eso ocurrió entre que vio la luz la edición española de Los cantares de gesta franceses y la aparición del texto publicado por la librería y editorial parisina Nizet: en el año 1951, Jules Horrent publicó un par de libros magníficos, La Chanson de Roland dans les littératures française et espagnole au Moyen Âge y Roncesvalles. Étude sur le fragment de cantar de gesta conservé à l'Archivo de Navarra (Pampelune). El primero de ellos pudo ser utili-

4. Se trata de Riquer (1952a). Cfr. Isabel de Riquer, «Prólogo» (Riquer 2009: 18-19).

5. El «propósito del autor» se puede leer, traducido, en la edición de Riquer (2009: 39-40). zado por Riquer, cuando ya había entregado a la imprenta el original de su obra; el relativo a Roncesvalles, ligeramente posterior, llegó demasiado tarde. Las Reliquias de la poesía épica, de R. Menéndez Pidal también son de 1951, pero Riquer no parece haberlas utilizado, ya que el tema se desviaba de sus propósitos. El importante estudio de Dámaso Alonso que daba a conocer la Nota Emilianense es de 1954, el librito de Jean Rychner sobre el arte épico de los juglares vio la luz en 1955; los Coloquios de Roncesvalles aparecieron en 1957 (se acabaron de imprimir el 19 de junio), aunque la reunión de los especialistas que contribuyen en el volumen es dos años anterior: ${ }^{6}$ en ellos R. Menéndez Pidal expuso algunas muestras de los estudios que estaba llevando a cabo sobre la Chanson de Roland y el tradicionalismo... Todas ellas, y otras más, eran investigaciones «originales» y «decisivas» que obligaron a Riquer (1957) a revisar y reelaborar el texto español para su publicación en francés.

El tercer pilar del programa de Literaturas románicas es la narrativa, en la que se incluyen la materia de Roma y la materia de Bretaña, aunque la importancia y el atractivo de las aventuras del rey Arturo y sus caballeros con frecuencia desequilibran la balanza a favor del reino de Camelot. Y así ocurrió con el tercer volumen de la Antología de textos literarios románicos medievales (Riquer 1952b), dedicado a la materia de Bretaña. Luego vendrían numerosos artículos, a partir de 1955, en los que Riquer anotaba o aclaraba diferentes versos de los romans de Chrétien de

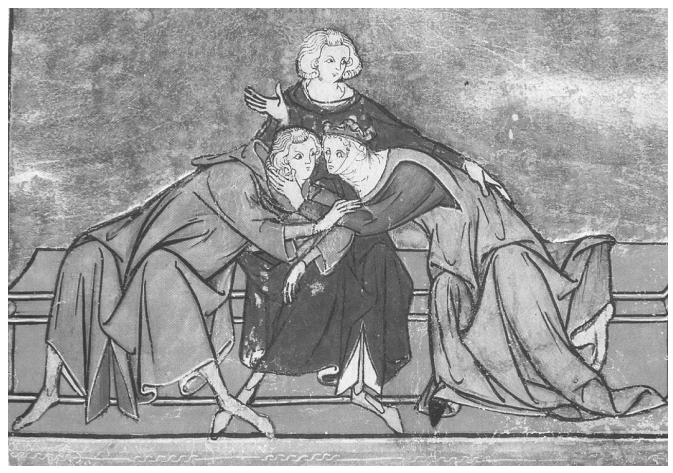

El primer beso de Lanzarote y Ginebra.

6. Véase Horrent (1951a y 1951b), Menéndez Pidal (1951), Alonso (1954), Rychner (1955), Menéndez Pidal (1956 [1957]), 
Troyes, o aspectos relativos a la difusión de las obras: son trabajos llenos de sabiduría, en los que se traslucen los comentarios y observaciones de clase. Todo ello daría lugar a la traducción de Perceval o El cuento del Grial (Riquer 1961).

Durante muchos años, el estudiante de Literaturas románicas apenas dispuso de otras traducciones de textos franceses y provenzales de la Edad Media que las que había hecho Riquer, y como manual no había otro que la parte dedicada al mismo periodo en la Historia de la Literatura Universal de Riquer y de J. M. Valverde (1957-59), obra que, dicho sea de paso, tendría un gran éxito y varias reediciones.

A los ejemplos aducidos se pueden añadir otros. Desde 1942, Riquer enseñaba también Literatura española, de manera que el catalán y el gallego-portugués no quedaban desasistidos, ya sea por su presencia en el programa de «Románicas», o en el de «Hispánicas». Pero no es ése el aspecto al que quiero referirme. Con frecuencia se olvida la vertiente de hispanista del maestro, buen conocedor de nuestra Edad Media y del Siglo de Oro, quizás por el florecimiento que en años más recientes han tenido los estudios de Literatura española medieval, quizás empañada por el relieve de Riquer en los estudios sobre Cervantes y el Quijote. Sin embargo, es necesario recordar que del año 1943 es su edición del Tesoro de Sebastián de Covarrubias, la antología de la prosa de fray Antonio de Guevara, un artículo sobre Petrarca y la Crónica sarracina de Pedro del Corral y una nota al Quijote, y del año siguiente es su primera edición de la novela de Cervantes; ${ }^{7}$ luego vendrán Calderón y Camoens, Fray Luis de León, el Arcipreste de Talavera, Juan de Mena, el Cid... Todo ello, antes de 1950, y alternando con trabajos sobre literatura catalana y provenzal. El Cavallero Zifar, Francisco de Luque Fajardo o Don Juan Manuel, Triste deleytación, Juan Boscán, Fernando de Rojas y un larguísimo etcétera dejan de manifiesto que el profesor no se había olvidado de las materias ajenas al medievalismo en unos casos o al hispanismo y en especial al Siglo de Oro. ${ }^{8}$ Las obras

7. Se trata, respectivamente, de Riquer (1943a, 1943b, 1943c, 1943d y 1944b).

8. La enumeración no es, ni mucho menos, exhaustiva.

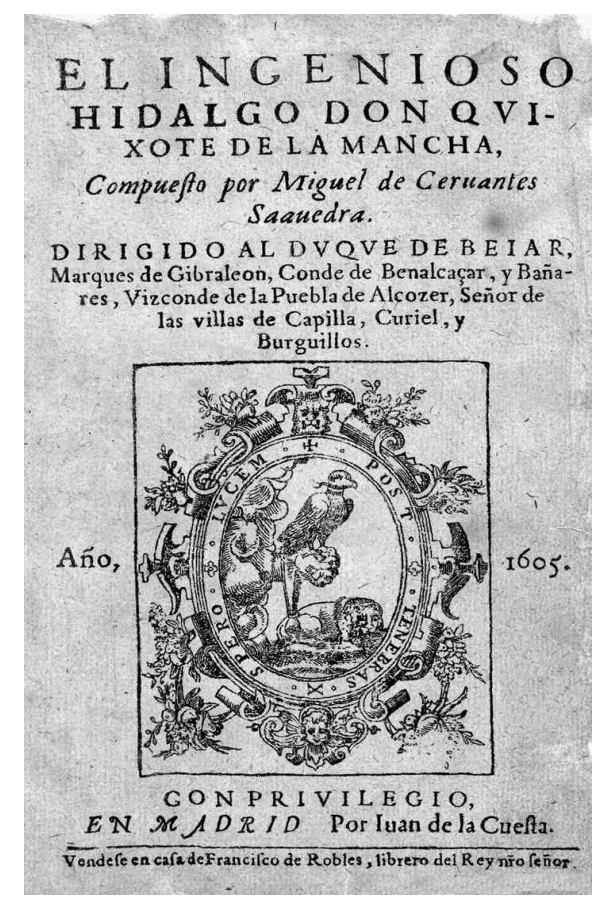

Portada de la primera edición del Quijote.

de muchos de los autores citados no habían sido objeto de una edición moderna, y Riquer facilitó el acceso de esos textos a los estudiosos y a los estudiantes. Y es bien sabido cómo la edición del Quijote se convirtió en un modelo de anotación sucinta, esencial, que no interfería en la lectura y que facilitaba enormemente la comprensión del texto: fue ésa una de las razones que hizo que su edición se haya mantenido en el mercado de forma ininterrumpida desde 1944 hasta nuestros días; es decir, más de setenta años sin perder vigencia, y tanto en ediciones populares, como en lujosos volúmenes «de artista». Y por si eso fuera poco, en $195^{8}$ publicó por primera vez su Introducción a la lectura del Quijote, que luego fue reeditada en numerosas ocasiones y en varias editoriales. ${ }^{9}$ El Quijote se convirtió, así, en otro de los grandes temas frecuentados a lo largo de los años, y fruto de las lecturas y re-

Véase Riquer (1945a, 1945b, 1946, 1949a, 1949b, 1949c, 1953, 1955a, 1955b, 1956, 1957a, 1957b y 1959).

9. Riquer (1958). Formaba parte de la edición del Quijote de la editorial Labor de Barcelona. Después sería publicada de forma exenta con el título de Aproximación al Quijote por Teide, Barcelona, 1977, con numerosas reediciones, y por Salvat, Barcelona, 1970 (con prólogo de Dámaso Alonso). 
lecturas fueron los numerosos y esclarecedores trabajos que dedicó a la novela cervantina.

Me he detenido en unos pocos ejemplos tempranos de la actividad académica y docente de Riquer. Es posible que parezcan muestras tempranas y que no sean representativas de la ingente labor realizada por el maestro. Pero lo cierto es que los temas, las líneas de investigación, se mantienen a lo largo del tiempo, en paralelo a la docencia. Poco a poco se produce un distanciamiento de la Literatura española, aunque se mantiene la fidelidad a Cervantes, quizás porque poco a poco el profesor Riquer había dejado de impartir las materias de Hispánicas. A la vez, se puede señalar cómo van adquiriendo su forma definitiva trabajos iniciados treinta o cuarenta años antes: la antología de los trovadores, con un extenso estudio inicial, aparece en tres volúmenes en 1975, treinta y cinco años después de los primeros pasos sobre Bernart de Ventadorn, y es traducida al francés en 2013.10 Una nueva versión de los cantares de gesta franceses vio la luz, de nuevo en español, en Gredos en 2009, medio siglo después de la primera edición; aunque sin grandes cambios desde la traducción de 1957, lo que indica la vigencia en general del libro. El Perceval de Chrétien fue publicado con las Continuaciones del Cuento del Grial en 1989, con un prólogo en el que Riquer recoge y aquilata sus ideas de los treinta años de estudio transcurridos desde que apareció la traducción en Austral. Tanto para la nueva edición en español de los cantares de gesta franceses como en la nueva versión de la obra de Chrétien y sus continuadores, Riquer contó con la ayuda de su hija Isabel, ya reconocida especialista en el mundo de las Literaturas románicas (Riquer 1989 y 2009). Y por lo que respecta al Quijote, en el 2003 nos ofreció una guía para leer a Cervantes que se centra en la novela, retomando temas ya esbozados, o desarrollados

\footnotetext{
10. Riquer(1975) después ha sido reimpreso por Ariel, en 1983 y 1989. El primer volumen de la traducción francesa ha sido publicado en los Cahiers de Carrefour Ventadour, 2013, con prefacio de Pierre Bec y edición de Dominique Billy, Luc de Goustine, Walter Meliga y Peter Ricketts; las traducciones del español han sido realizadas por Roland Béhar, Françoise Crémoux, Virginie Dumanoir, Cécile Iglésias y Nelly Labère.
}

desde cuarenta años antes (Riquer 2003). Bastarían estos ejemplos para extraer unas conclusiones o, si se prefiere, para establecer un perfil académico e investigador de Riquer. Ya señalaba Dámaso Alonso en 1965 que era

Caso portentoso este de Martín de Riquer, preciso y riguroso en investigaciones de último pormenor, con capacidad a la par de intuición de grandes rasgos definidores de obras, escritores o épocas; que escribe para el más aquilatador especialista cuando hay que dirigirse a él, o, adaptándose, sin perder rigor científico, al público culto en general, cuando es a éste a quien hay que hablar.

(Alonso 1965: 110)

Y añadía más adelante que

El público de Martín de Riquer son a veces media docena de sabios que han pasado su vida con las cabezas inclinadas sobre un acotado problema del fondo de la Edad Media; otras veces, amplias multitudes sedientas de que alguien —ese alguien que en tan pocos casos se encuentra - les sepa enseñar.

(Alonso 1965: 132)

En efecto, Riquer es una auctoritas filológica: en un reciente diccionario biográfico de los trovadores publicado en Italia (Guida \& Larghi 2014), su nombre es citado con extraordinaria frecuencia; posiblemente es el que acapara más referencias, y además figura al frente de varias entradas, como responsable de las únicas ediciones existentes de no pocos trovadores. Su presidencia de la Société Rencesvals, dedicada al estudio de la épica románica, fue la más clara muestra del reconocimiento internacional en el ámbito de los cantares de gesta." Cualquier aproximación a la obra de Chrétien de Troyes tiene siempre en cuenta las aportaciones de Riquer. En fin, no hay estudio serio sobre el Quijote que no incluya al menos dos docenas de referencias bibliográficas de nuestro maestro, sin contar que las ediciones de la novela de Cervantes tienen siempre muy presentes las lecturas y anotaciones de Riquer.

11. La relación de Riquer con la Société Rencesvals es objeto de una nota de Anna M. Mussons (1989: IVvi). Fue presidente entre 1978 y 1980; después fue nombrado Presidente de honor. 
¿Y qué decir de la Literatura catalana o de la heráldica y del armamento? Riquer constituye una base necesaria para la construcción de cualquier edificio filológico, grande o pequeño.

Por otra parte, es evidente que Riquer no rehuyó en ningún momento la divulgación de nivel académico, pues sus lectores «imaginarios», en los que pensaba al escribir, fueron siempre los estudiantes de sus cursos de la Universidad de Barcelona. Bien se podría decir que escribía «como daba clase»»: no resulta difícil reencontrar la voz del profesor en medio de la letra impresa, y quienes asistimos a sus clases podríamos reconstruir la entonación, la gestualidad, la ironía en muchas de sus frases y un retenido sentido del humor en otras. Todo ello da como resultado la amenidad y la claridad estilística de Riquer, que tantas veces ha sido señalada: lenguaje llano y profundidad de ideas. Así eran sus clases.

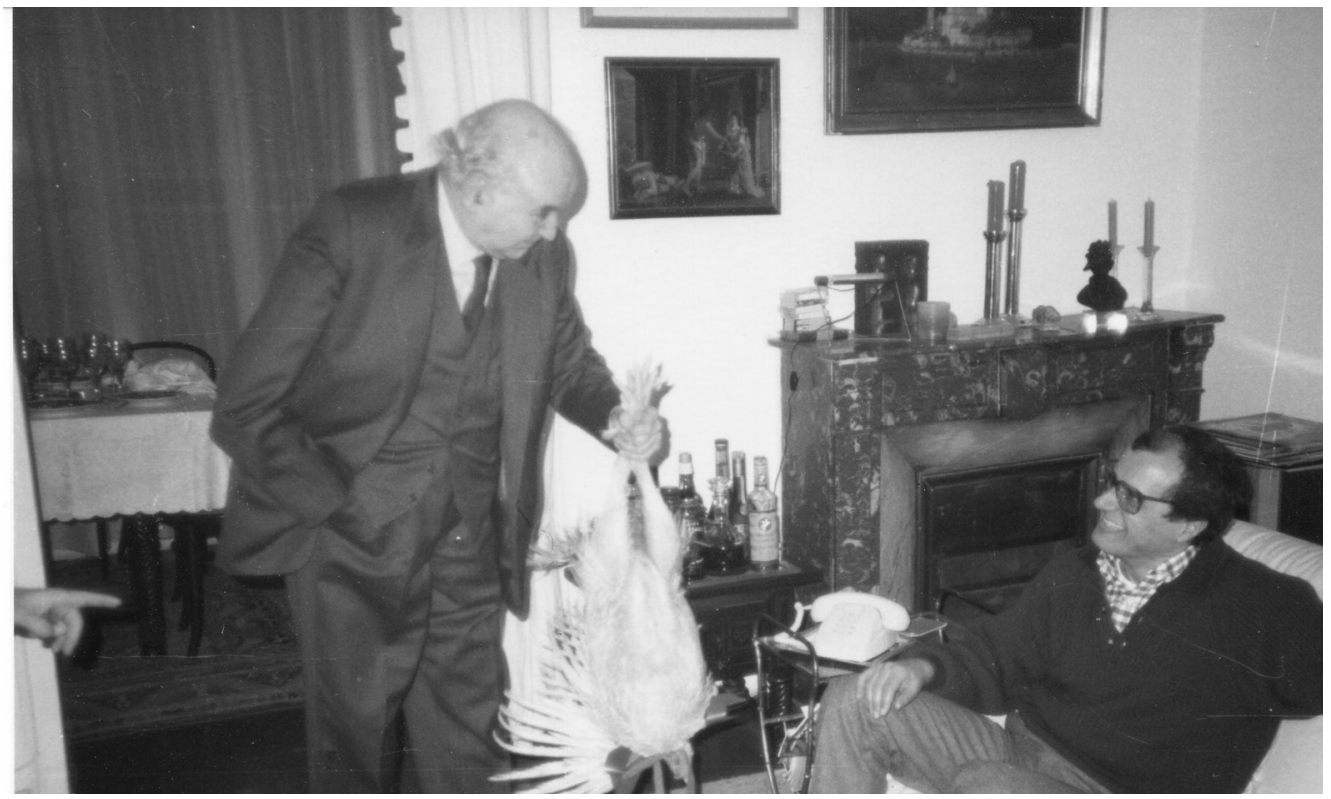

Martín de Rlquer hace entrega de un pavo a Jaume Auferil. 


\section{Bibliografia citada}

Alonso, Dámaso, 1954: «La primitiva épica francesa a la luz de una Nota Emilianense», Revista de Filología

Española, 37, 2-94.

Alonso, Dámaso, 1965: «Contestación» a Martín de Riquer, Vida caballeresca en la España del siglo Xv. Discurso de ingreso en la Real Academia Española, Madrid: Real Academia Española.

Gatell, Cristina \& Glòria Soler, 2008 Martín de Riquer. Vivir la literatura, Barcelona: RBA.

GUIDA, Saverio \& Gerardo LARGHI, 2014: Dizionario biografico dei trovatori, Mòdena: Mucchi.

Horrent, Jules, 1951a: La Chanson de Roland dans les littératures française et espagnole au Moyen-Âge, París: Les Belles Lettres.

HORRENT, Jules, 1951b: Roncesvalles. Études sur le fragment de cantar de gesta conservé à l'Archivo de Navarra (Pampelune), París: Les Belles Lettres.

Menéndez Pidal, Ramón, 1951: Reliquias de la poesía española, Madrid: Espasa-Calpe.

Menéndez Pidal, Ramón, 1956 [1957]: «La Chanson de Roland desde el punto de vista del tradicionalismo», Coloquios de Roncesvalles, Saragossa: Diputación Foral de Navarra, 15-37.

Mussons, Anna M., 1989: «Martín de Riquer y la Société Rencesvals», Anthropos, 92, 68-69.

Riquer, Martí de, 1934: L'Humanisme català (1388-1494), Barcelona: Barcino.

RiQuer, Martín de (ed.), 1935: Antoni Canals, Scipió e Anibal, De Providència, De arra de ànima, Barcelona: Barcino.
RIQuer, Martín de (ed.), 1940: Bernartz de Ventadorn, Poesías, Barcelona: Yunque.

RiQuer, Martín de (ed.), 1943a: Sebastián de Covarrubias, Tesoro de la lengua castellana o española, Barcelona: Imprenta Horta.

RiQuer, Martín de (ed.), 1943b: Antonio de Guevara, Prosa escogida, Barcelona: Miracle.

Riquer, Martín de, 1943c: «El Africa de Petrarca y la Crónica sarracina de Pedro del Corral»», Revista de Bibliografía Nacional, 4, 293-95.

RIQUeR, Martín de, 1943d: «'Echar a galeras' y el pasaje más oscuro de Quijote», Revista de Filología Española, $27,82-86$.

RiQuer, Martín de (ed)., 1944a: Las albas provenzales, Barcelona: Entregas de poesía.

Riquer, Martín de (ed.), 1944b: Migue de Cervantes, Don Quijote de la Mancha, Barcelona: Juventud, 3 vols.

RiQuer, Martín de (ed.), 1945a: Pedro Calderón de la Barca, La vida es sueño, Barcelona: Juventud.

Riquer, Martín de (ed.), 1945b: Luis de Camoens, Poesía castellana y fragmentos de «Los Lusíadas» según la versión de Enrique Garcés (1591), Barcelona: Montaner y Simón.

RiQueR, Martín de (ed), 1946: «Dos manuscritos con poesías de fray Luis de León», Analecta Sacra Tarraconensia, 19, 241-261.

Riquer, Martín de (ed), 1947: Obras completas del trovador Cerverí de Girona, Barcelona: Instituto Español de Estudios Mediterráneos.

RIQUeR, Martín de, 1948a: La lírica de los trovadores, antología comentada, t. I: Poetas del siglo XII, Barcelona: CSIC.
RIQUeR, Martín de, 1948b: Resumen de literatura provenzal trovadoresca, Barcelona: Seix Barral.

Riquer, Martín de (ed.), 1949a: Alfonso Martínez de Toledo, Arcipreste de Talavera: Corbacho o reprovación del amor mundano, Barcelona: Selecciones Bibliófilas.

RiQuer, Martín de (ed.), 1949b: Juan de Mena, La Ylíada en romance según la impresión de Arnao Guillén de Brocar (Valladolid, 1519), Barcelona: Selecciones Bibliófilas.

Riquer, Martín de, 1949C: «iDios, qué buen vassallo, si oviesse buen señor!»》, Revista Bibliográfica y Documental, 3 257-60.

RIQUER, Martín de, 1952a: Los cantares de gesta franceses (sus problemas, su relación con España), Madrid: Gredos.

RiQuer, Martín de, 1952b: Antología de textos literarios románicos medievales, III, Materia de Bretaña, Barcelona: Facultad de Filosofía y Letras.

RIQUer, Martín de (ed), 1953: El cavallero Zifar, Barcelona: Selecciones Bibliófilas, 2 vols

Riquer, Martín de (ed.), 1955a: Francisco de Luque Faxardo, Fiel desengaño contra la ociosidad y los juegos, Madrid: Real Academia Española, 2 vols.

Riquer, Martín de (ed), 1955b: Obras de don Juan Manuel, con José Ma Castro y Calvo, vol. I, Barcelona: CSIC.

RiQuer, Martín de (ed), 1956: «Triste deleytación, novela castellana del siglo Xv», Revista de Filología Española, 40, 33-65.

Riquer, Martín de (ed), 1957a: Obras poéticas de Juan Boscán. Edic. crítica en col. con A. Comas y J. Molas, Barcelona: Facultad de Filosofía y Letras. 
RIQUeR, Martín de, 1957b: «Fernando de Rojas y el primer acto de La Celestina», Revista de Filología Española, 41, 373-95.

Riquer, Martín de, 1957c: Les chansons de geste françaises, trad. de Irénée Cluzel, París: Nizet.

RIQUER, Martín de, 1958: «Introducción a la lectura del Quijote», dins de Migue de Cervantes, El ingenioso hidago don Quijote de la Mancha, Barcelona: Labor, vol. 1, VII-LXVIII.

RIQUer, Martín de (ed.), 1959: Fernando de Rojas, «La Celestina»y «Lazarillos», el primero y el de Juan de Luna, Barcelona: Vergara.

Riquer, Martín de, 1960: El cantar de Roldán, traducción del texto francés del siglo XII del manuscrito de Oxford, Madrid: Espasa-Calpe.
Riquer, Martín de (ed.), 1961: Chrétien de Troyes, Perceval o El cuento del Grial, Madrid: Espasa-Calpe.

RIQUeR, Martín de, 1975: Los trovadores, historia literaria y textos, Barcelona: Planeta, 3 vols [reimpreso por Ariel, en 1983 y 1989].

RiQuer, Martín de (ed), 1989: El Cuento del Grial de Chrétien de Troyes y sus Continuaciones. [Prólogo y traducción del Cuento del grial por Martín de Riquer; traducción de las Continuaciones e Índices por Isabel de Riquer], Madrid: Siruela.

Riquer, Martí de, 2003: Para leer a Cervantes, Barcelona: Acantilado.

Riquer, Martín de, 2009: Los cantares de gesta franceses, trad. de M. Reina Bastardas, Madrid: Gredos.
RIQUeR, Martín de \& José M. VALVERDE, 1961: Historia de la Literatura Universal, Barcelona: Noguer, 3 vols.

RYCHNER, Jean, 1955: La chanson de geste. Essai sur l'art épique des jongleurs, Ginebra - Lille: Droz - Giard.

VeLA, Leonor, 1991: Bibliografía de Martín de Riquer, Studia in honorem prof. M. de Riquer, Barcelona: Quaderns Crema, IV, 733-59.

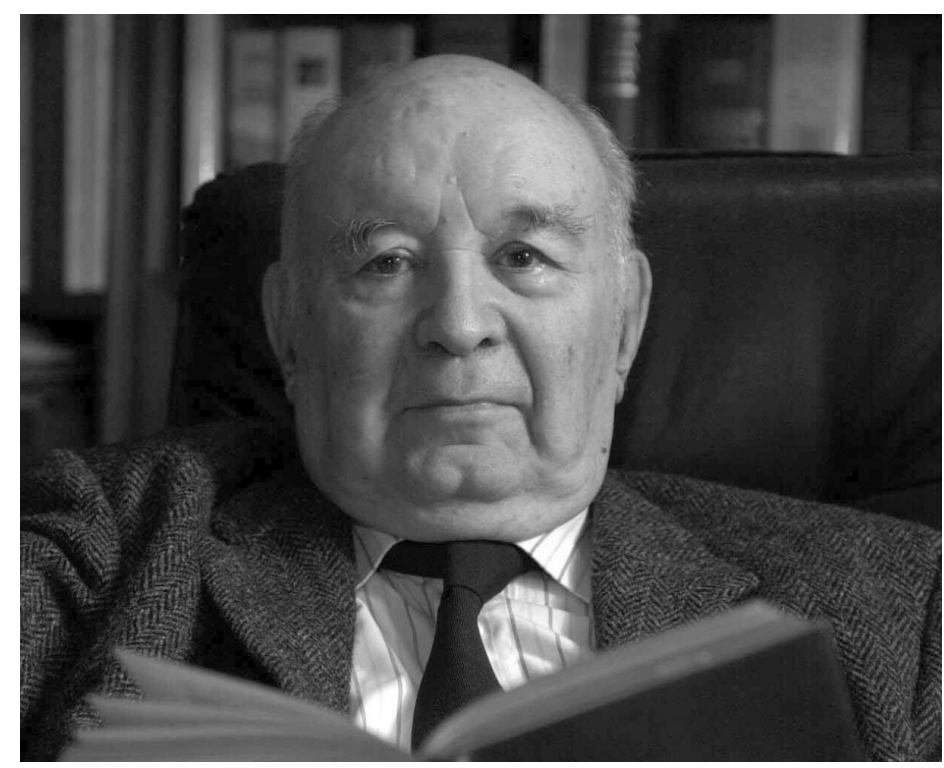

